\title{
ENTRE EL DESEO Y LOS SACRIFICIOS. El DISPOSIIIVO DEL AMOR ROMÁNTICO EN El RELATO dE LAS MUJERES'
}

\section{BETWEEN THE DESIRE AND THE SACRIFICES. THE DEVICE OF ROMANIIC LOVE IN WOMAN'S TALE}

MARÍA FLORENCIA ACTIS ${ }^{2}$, MARIIA FLORENCIA CREMONA ${ }^{3}$ Y ROCIO GARIGIIO ${ }^{4}$

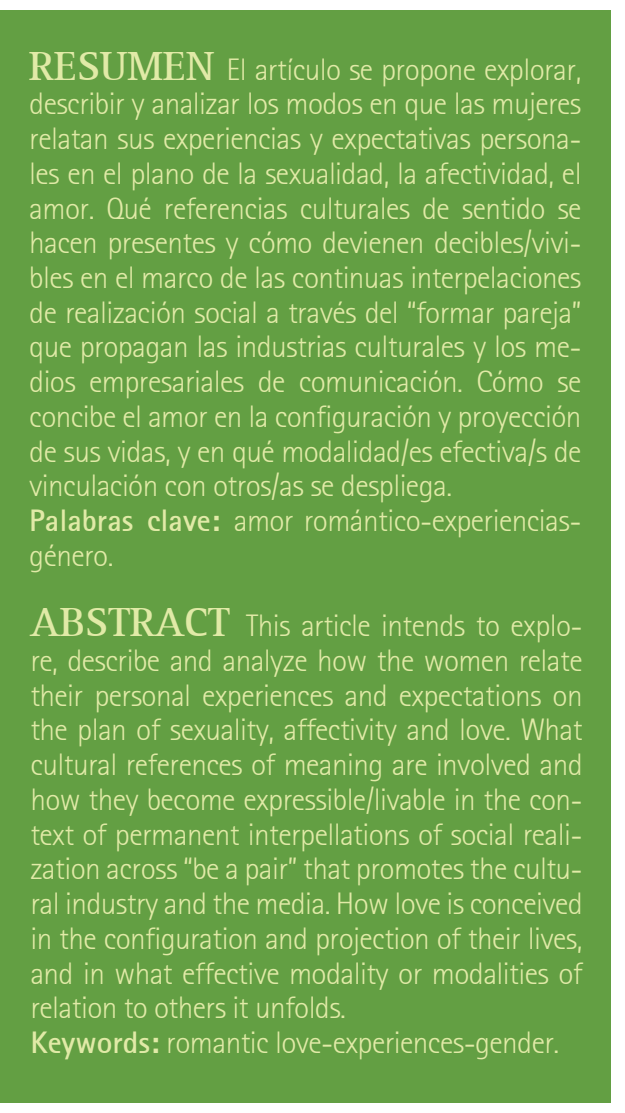

' Artículo enviado el 15 de mayo de 2018 y aprobado el 12 de julio de 2018.

\begin{abstract}
${ }^{2}$ Profesora y Licenciada en Comunicación Social y Especialista en Peridiodismo, Comunicación Social y Género de la FPyCS, UNLP. Integrante del Laboratorio de Investigaciones en Comunicación y Género. Facultad de Periodismo y Comunicación Social. Universidad Nacional de La Plata. E-mail: florenciactis@gmail.com
\end{abstract}

${ }^{3}$ Integrante del Laboratorio de Investigaciones en Comunicación y Género. Facultad de Periodismo y Comunicación Social. Universidad Nacional de La Plata. E-mail: cremona23@yahoo.com

\footnotetext{
${ }^{4}$ Laboratorio de Investigaciones en Comunicación y Género. Facultad de Periodismo y Comunicación Social. Universidad Nacional de La Plata. E-mail: rogariglio@ gmail.com
}

El amor, concebido como fatum, fatalidad, crueldad y pasión, ha sido objeto de intensos debates filosóficos, antiguos y modernos. Sin embargo, la representación del amor como surgimiento de fuerzas primitivas e inocentes no es exclusiva de este campo y de los estudios feministas. Ha protagonizado dramas, comedias y novelas policiales de la industria cultural, de la literatura y el cine; ha sido -y sigue siendonudo argumental en las crónicas de la industria mediática. Situamos al "amor romántico" en esas tramas discursivas, comunicacionales. Reconocemos sus distintas modalidades de producción y naturalización de las violencias de género. Las prerrogativas para alcanzar el amor como aspiración existencial -el amor de pareja- aparecen como relato implícito de las violencias de género.

El artículo analiza los relatos de mujeres cis-heterosexuales de sectores medio-urbanos de la ciudad de La Plata y Mar del Plata, recogidos en el marco de grupos focales en los que se abordó la tramitación de sus relaciones amorosas y sexualidades. La técnica de los grupos focales se inscribe en la metodología de un proyecto de investigación más amplio desarrollado por el equipo del Laboratorio de Comunicación y Género de la Facultad de Periodismo y Comunicación Social (UNLP). Este profundiza en los sentidos que imprime el discurso social (novelas del "prime time" y suplementos femeninos) respecto del amor romántico como fundamento ideológico de la violencia de género; en las tensiones entre los nombramientos y representaciones hegemónicas, donde se propone y perpetúa la subalternidad de lo femenino/lo no heterosexual, y las prácticas sexo afectivas en general, y de las participantes de los grupos focales en particular.

No es objetivo de este artículo abordar el vínculo entre los consumos de la industria cultural y las experiencias de las informantes, sino recuperar los sentidos del amor romántico que aparecen en sus relatos. De este modo, se pretende dilucidar los modos en que se gestionan y negocian los vínculos de pareja y cómo son percibidos simbólicamente. 
De Prácticas y discursos

Universidad Nacional del Nordeste

Centro de Estudios Sociales

Año 7, Número 10, 2018, Octubre

ISSN 2250-6942

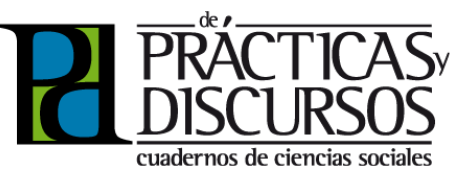

POSICIONAMIENTOS TEÓRICO-POLITICOS

\section{LA REVISIÓN FEMINISTA DEL PODER}

El trabajo se inscribe en una perspectiva teórica transdisciplinaria, abonada por aportes clásicos y emergentes de los estudios de género. Diversos posicionamientos teóricos centrados en la pregunta por el poder y la hegemonía, desde un enfoque feminista. Consideramos que cada vez que hablamos de género, hablamos de poder (Pateman, 1986; Amigot Leache y Pujal i Llombart, 2009; Rodríguez Magda, 1999; Cremona, 2016). De las tramas de poder impresas de hecho a partir de normativas o pautas culturales sujetas a la identificación sexual que las instituciones hacen de las personas, y que las personas hacen de si mismas enmarcadas en procesos históricos. El género es también un concepto móvil que estamos reelaborando críticamente en nuestra vida cotidiana, mediante el ejercicio de politizar nuestras sexualidades e identidades, y de sexualizar nuestras prácticas político-militantes. "Tal perspectiva implica desmarcarse de los criterios que hacen de la sexualidad una invariable, para sostener la problemática del deseo, de las prácticas eróticas-amatorias y las formas de subjetividad que se construyen como parte del campo socio-histórico" (Fernández y Siqueira Peres, 2013: 18). Nuestra perspectiva adhiere al compromiso feminista de realzar en el análisis teórico aquella economía del poder entre los géneros, cristalizada en roles y estereotipos activos, que en términos de Joan Scott (1996: 289) constituyen "la forma primaria de relaciones significantes de poder". En este sentido, "la revisión de los estereotipos de género y sus consecuencias no sólo supone el descorrimiento de los velos de la invisibilización, sino también de los factores estructurales que inciden indirectamente en tales ocultamientos" (Femenías, 2009: 21).

Sin embargo, y volviendo a los aportes de Scott, el género solo se constituye en una categoría útil para el análisis social, presente e histórico, en tanto se la sitúe en contextos significantes reducidos. "No es un concepto universalmente aplicable con parámetros o referentes fijos (...) el llamado 'lenguaje de género' no puede extraerse de diccionarios universales; son los significados especificos los que debemos extraer (...) el género es una pregunta abierta sobre la manera en que se establecen esos significados, lo que denotan y en qué contextos lo hacen" (Scott, 2008: 
110). La revisión feminista del poder en el terreno de la investigación social debe procurar entonces desentramar los modos en que el género -y por ende el sexo- es codificado y puesto en acto más acá de los entornos sociales, geográficos, temporales, idiosincráticos; con sus configuraciones, condicionamientos y problemáticas determinadas.

Ponemos en valor este concepto, entendiendo que es el punto nodal para potenciar nuestras prácticas investigativas, educativas y comunicacionales; pero también para seguir echando luz sobre la producción de desigualdades, asimetrías y jerarquías constitutivas de las instituciones patriarcales.

\section{EL CONTRATO CONYUGAL}

Si las concepciones del amor como ejercicio de la intimidad se fusionan con el ideal romántico en las narrativas dominantes, ¿por qué la imaginería de las relaciones sexo afectivas confluye en la consumación de la conyugalidad monógama, ya sea el matrimonio o el concubinato?; ¿qué tramas del erotismo permanecen clandestinizadas o socavadas por el relato de esta conyugalidad determinada, como corolario del encuentro entre personas?, ¿qué tramas de sentido configuran al amor romántico como parte intrínseca de "la realización" y "la plenitud"? 0, por el contrario, de la subordinación social de las mujeres y explicación de las violencias que contra ellas se ejercen.

Resulta primordial comprender que la pregunta por el amor romántico conlleva indefectiblemente a los procesos de estabilización de una identidad, y de un sujeto femenino y masculino. Mari Luz Esteban y Ana Távora reintroducen la noción de "poder afectivo" o "de los afectos" para explicar por qué las mujeres ocupan, sostienen y permanecen en lugares de "afiliación servil" en el marco de sus parejas, conyugales o no. Plantean que "la adscripción al poder afectivo llevará a las mujeres a establecer un tipo de relaciones intimas que van a convertirse en la principal fuente para construir sus identidades; relaciones entre dominados y dominadores" (2008: 65). Ese poder, definido por su capacidad de sentir y dar afecto, aprendido, practicado y afirmado desde la niñez, como citan las autoras, es organizador de la experiencia y constitutivo de la subjetividad (2008: 65). El habitar, apropiarse e incluso patrocinar este lugar servicial y abnegado no se explica tan solo mediante la represión o postergación de los "deseos 
De Prácticas y discursos

Universidad Nacional del Nordeste

Centro de Estudios Sociales

Año 7, Número 10, 2018, Octubre

ISSN 2250-6942

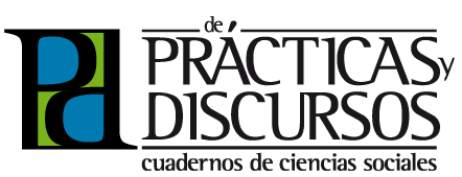

propios", sino también mediante la generación y modulación del deseo de realización a través de estas tareas, "convirtiéndola en una suerte de servidora voluntaria".

Se considera el contrato conyugal como un organizador en el ejercicio y tramitación de la sexualidad; por ende, en el ejercicio y tramitación de un modo de ser y estar en sociedad, que de acuerdo al género inviste diferentes y desiguales obligaciones. Este tipo de amor, más allá del eventual componente emocional, "es entonces un negocio de dos; de modo que se habla de los amantes como 'socios' (...) las parejas esperan que cada quien haga su trabajo y exista reciprocidad en las responsabilidades y los beneficios" (Rodríguez Salazar, 2012: 163). ¿Qué es lo visible del contrato conyugal? Lo visible es la implicancia en un proyecto de vida en común que incluye procrear, criar y amar a la descendencia, basado en la noción de coexistencia armónica y complementariedad de funciones. La parte invisible es la violencia y los mecanismos de naturalización de una disparidad contractual. El matrimonio es el lugar donde se generan condiciones para las formas inequitativas de apropiación del capital cultural, formas de acceso desigual a los circuitos de calificación laboral y a los centros de poder, etc. El lugar de control del erotismo de la esposa, "como escenario específico de las relaciones de poder entre los géneros sexuales donde pueden detectarse discursos legitimadores de la desigualdad" (Chantefort, 2017: 382).

Es interesante la lectura de Mariana Palumbo sobre el vínculo poderviolencia-amor, ya que deshace y complejiza la dicotomía dominador-dominada, y la figuración de opuestos binarios complementarios. Reconsidera a la mujer, novia/amante, desde su capacidad de agencia en el marco de la organización social, cultural, económica, institucional vigente, produciendo activamente prácticas y sentidos vinculados a sus relaciones amorosas. Palumbo cataloga de "victimistas" a las lecturas académicas hegemónicas donde la mujer es exclusivamente receptora pasiva de agresiones diversas propagadas por un varón, y corre el eje al carácter relacional de la violencia y al rol que ocupan las mujeres en la reproducción de las mismas.

Por ello, para el análisis de los grupos focales se tendrán en cuenta las variables de poder estructurales que se replican en el seno mismo de las relaciones amorosas, y las particulares formas de sujeción sexual supuestas para las mujeres, pero también las variables de agenciamiento, resistencia y posibilidad de resignificar que también forman parte de sus experiencias y sus narrativas. 


\section{(DES)MITIFICAR EL AMOR}

Respecto al mito, este cristaliza sentidos que una sociedad determinada esboza como un modo de hacer inteligible su realidad. La particularidad del discurso mítico se comprende a la luz de "la naturaleza" imperativa de sus significaciones, puesto que se solidifican rituales, percepciones, valoraciones y se arrogan modos legitimos de clasificación del mundo tal como lo conocemos.

Normativizan y establecen el guion de las prácticas socioculturales y como consecuencia, disciplinan géneros y sexualidades. "El componente mitológico e imaginario no es una simple superestructura, menos aún una ilusión, sino una realidad humana y profunda" (Morin, 1998: 2).

Ana Maria Fernández (1993) entiende a los mitos como las piezas fundamentales del rompecabezas social, que regulan, organizan, estipulan, y no solo prohiben, en el obrar de los individuos. Lejos de agotarse en la abstracción del "inconsciente colectivo", traspasan el velo de lo simbólico, y configuran relaciones objetivas, subjetivas e intersubjetivas entre cada persona y la sociedad, entre el espacio público y el privado. Su vigencia se logra por insistencia y repetición a partir de los múltiples focos y lugares de emisión discursiva del espacio social; por operaciones de violencia simbólica, amordazando otros sentidos, diversos y singulares, que se construyen por fuera del mito.

El amor romántico es, en este sentido, un ideal mitificado por la cultura (Herrera Gómez, 2007) que operativiza una cierta organización de los vínculos sexo-afectivos bajo la lógica de la subyugación y opresión del universo de lo femenino desde un ordenamiento jerárquico patriarcal. La potencia performativa de los mitos del amor alcanza el plano de las emociones; habiendo en los relatos míticos que edifican los imaginarios culturales, una estructura de sentimiento y expresiva que es fuente y paradigma de emociones.

\section{LA MAQUINARIA DEL DESEO}

Partimos de concebir al deseo no como patrimonio exclusivo del inconsciente del sujeto sino, tal como plantea Paul Preciado, un artefacto modelado culturalmente por la violencia social, los incentivos y las recompensas, pero también por el miedo a la exclusión. Desde esta definición nos interpela: "desconfía de tu deseo, sea cual sea (...) el deseo no es una reserva de verdad, sino el pro- 
De Prácticas y discursos

Universidad Nacional del Nordeste

Centro de Estudios Sociales

Año 7, Número 10, 2018, Octubre

ISSN 2250-6942

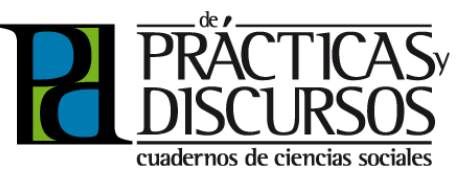

ducto de complejos mecanismos de construcción política" (Preciado, 2013: 164). Cabe preguntarnos hasta qué punto el deseo sexual resulta una expresión del orden individual, y no una marca (más) en el sujeto del orden simbólico dominante, del lenguaje como función constitutiva del orden social (Suniga y Tonkonoff, 2012). Aquello que se experimenta como manifestación natural del deseo sexual se inscribe en un régimen bio-político (Foucault) que preestablece, contornea y reactualiza constantemente qué es lo deseable, y qué permanecerá excluido de este horizonte.

Vale enfatizar la imbricación capitalismo-patriarcado y su rol activo en la direccionalidad de estos procesos de modelización de deseos, de producción y distribución de emociones. El sexo, el romance y el matrimonio forman parte de un mercado de consumo. Quizás la razón por la que es tan dificil hallar relatos de vida alternativos a la pareja cis-heterosexual y monógama es porque esos relatos no juegan ningún rol fuerte en el mercado de consumo (IIlouz, 2012). No obstante, más allá de la efectividad de las fuerzas de conservación y reproducción operantes sobre la maquinaria de los deseos, esas fuerzas pueden contrarrestarse por efecto de otras, que fracturen, fuguen e imaginen nuevas formas de deseo. Consideramos que los distintos activismos feministas en nuestro pais y el mundo vienen encarnando esas fuerzas, oponiendo resistencias al sistema capitalista y patriarcal, ensayando otros relatos de vida deseables.

Nuestro proyecto de investigación contribuye a complejizar la pregunta por los fundamentos y operatorias de reactualización de esas desigualdades de género que se desprenden del deseo heterosexual y de la vida en pareja como proyecto vital. Es decir, de la heteronorma como forma de organización política y "la pareja" como modalidad legítima de alianza sexual.

\section{OBJETIVOS Y DECISIONES METODOLÓGICAS}

Para el análisis del amor romántico en tanto dispositivo de (auto) control de las sexualidades, y para desandar los modos singulares en que las informantes se sienten atravesadas/interpeladas por este, se tuvieron en cuenta tres ejes puntuales:

1) La vinculación amor/enamoramiento/deseo.

2 Los modos cotidianos en que se despliegan sus relaciones sexo-afectivas, teniendo en cuenta la variable sacrificial y "el trabajo doméstico no remunerado". 
3) El lugar simbólico y efectivo de "la pareja" en el proyecto de vida de las mujeres.

A los fines de indagar la producción, circulación y formas de internalización de discursos sobre el amor romántico, el proyecto de investigación del Laboratorio de Comunicación y Género (FPyCS, UNLP) se plantea, en primer lugar, la construcción de un corpus de análisis heterogéneo conformado por "superficies textuales" (Ficoseco, 2014). Este concepto, original de Figari (2011) y trabajado por Ficoseco, alude a un conjunto de discursos de diversas fuentes, soportes y temporalidades, que una vez agrupados permiten reconstruir la manera en que algo o alguien fue hablado en determinado momento. El término trae aparejada una concepción de los textos no como documentos, sino como acontecimientos discursivos. En este marco, "el texto es un espacio de significación, producción, dispersión y fijación de sentidos, de construcción de las posiciones de los sujetos en condiciones históricas especificas" (Ficoseco, 2014: 110).

En particular, desarrollaremos aquí los sentidos recogidos a partir de la realización de grupos focales que reunieron a mujeres residentes del casco urbano de la ciudad de La Plata y Mar del Plata, heterosexuales, o con experiencias amorosas heterosexuales, de entre 25 y 50 años, con distintos perfiles socio-culturales, todas con estudios secundarios completos, casi todas con un recorrido universitario. Se apuntó a recoger experiencias de mujeres adultas de clase media.

El recorte se propuso enmarcado en la integralidad del proyecto de investigación mencionado anteriormente. La demarcación etaria tiene que ver con mantener un amplio abanico generacional, pero que comparta cierto universo de la cultura mediática. En tanto que la decisión de indagar en los sentidos de la clase media con respecto al amor romántico responde a la intención de aportar a los estudios surgidos en los últimos años que abordan distintos aspectos de este sector social (Palumbo, 2015; Adamovsky, 2009; Chaves, 2005).

Retomamos la definición de Adamovsky (2009) para caracterizar la "clase media" como aquel sector social con posibilidades de movilidad económica ascendente y descendente, que posee un determinado capital cultural y que se identifica subjetivamente con la pertenencia a la clase media. Es decir, no se trata únicamente de la condición material de clase, sino de la autopercepción de perte- 
De Prácticas y discursos

Universidad Nacional del Nordeste

Centro de Estudios Sociales

Año 7, Número 10, 2018, Octubre

ISSN 2250-6942

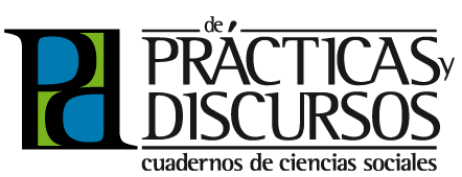

nencia y de la performatividad que se activa toda vez que alguien se identifica como parte intermedia de la sociedad.

El objetivo especifico de los grupos focales consistió en indagar cómo los sentidos sociales en torno al amor operan como argumentos vitales. Qué referencias culturales de sentido se hacen presentes y cómo devienen decibles/vivibles en el marco de las continuas interpelaciones de realización social a través del "formar pareja" que se propagan a través de la cultura mediática. De qué manera las dimensiones (definidas como) centrales del amor romántico -"la pareja", el deseo, el poder, las negociaciones- se ponen en juego en el intercambio de relatos.

Más allá de los cuestionamientos a la inclusión de los grupos focales como técnicas de estudio en Ciencias Sociales, lo cierto es que además de su utilización cada vez más frecuente en este campo, el ajuste de un método y unas técnicas a un objetivo de investigación no es apriorístico. En el caso puntual de nuestra investigación, de tipo cualitativa, recurrimos a dicha técnica porque nos permitió acceder a un conocimiento "desde el adentro" de los fenómenos sociales. Al modo en que los sujetos los viven y protagonizan. Acordamos en que construir la escena para el desarrollo de un grupo focal "no es otra cosa que diseñar un contexto comunicativo destinado no sólo a recabar información sobre las cuestiones pertinentes, sino también a provocar situaciones que pueden darse de forma natural y que serán precisamente objeto de análisis" (Gómez-Escalonilla, Huertas Bailén y Martínez Suárez, 2012: 873).

Operativamente se realizaron tres preguntas abiertas que permitieron la interacción de las participantes, y dieron lugar a que cada mujer pudiera compartir anécdotas que movilizara algo en las demás.

Primera/s pregunta/s: ¿Estás o has estado enamorada?, ¿de qué te enamoraste?, ¿qué es estar enamorada?

Segunda/s pregunta/s: ¿Qué han hecho ustedes por amor?, ¿qué han hecho sus parejas por ustedes?

Tercera pregunta: Proyecciones/horizontes. ¿Cómo, dónde y con quién/es se ven de acá a unos años?

Durante el transcurso de los grupos focales estuvieron presentes dos moderadoras del equipo de investigación, encargadas de proponer los ejes de conversación, procurando intervenir poco y 
alentar la discusión entre las informantes.

La estrategia de utilizar preguntas abiertas apuntó a trabajar en tópicos disparadores que permitieran que las participantes charlaran de modo informal sobre el amor, sin sentir que estaban siendo juzgadas o evaluadas. El clima de conversación fue relajado pese a la provocación e interpelación a "lo personal" de las preguntas. La duración de ambos grupos focales fue de entre 60 y 80 minutos.

\section{MUJERES "AMANTES" EN PRIMERA PERSONA}

\section{EL ENAMORAMIENTO}

La primera pregunta estuvo orientada a relevar nociones y experiencias en torno al enamoramiento. En ambos grupos generó la reacción de repreguntar si nos referíamos a un enamoramiento respecto de la pareja o de otro tipo de vínculo/actividad.

"Podemos empezar con definir qué es estar enamorada". (D., 46 años)

"Una puede estar enamorada de varias cosas. ¿Vos te referís a un amor de pareja o hacia los hijos, por ejemplo?”. (E., 49 años)

¿Hacia la pareja o hacia la vida que estás transitando? Imagino que te referís al amor de pareja”. (F., 32 años)

"Siento amor por las cosas que estoy haciendo a veces y es como el amor que siento por mi pareja. A veces en mi pareja digo 'uy qué embole, ¿será que tiene un ciclo la pareja, que tengo que seguir asi?'. Y de pronto lo que hago cotidianamente me gusta tanto que ahi encuentro el amor". (A.L., 35 años)

La necesidad de aclarar y demostrar que no comprenden el enamoramiento solo en términos sexo-afectivos la contextualizamos en una situación inicial del grupo focal, donde no había todavía un clima de relativa confianza y distensión para compartir de lleno algo "tan íntimo" y, además, donde es sabido que subyace una lectura crítica de sus respuestas por parte de las moderadoras. Cuando finalmente empezaron a responder la pregunta en sí, se fueron desplazando de las respuestas esperables o generales, para dejarse ver en el plano más íntimo con sus propias contradicciones. 
De Prácticas y discursos

Universidad Nacional del Nordeste

Centro de Estudios Sociales

Año 7, Número 10, 2018, Octubre

ISSN 2250-6942

\footnotetext{
${ }^{5}$ Integrante del Laboratorio de Investigaciones en $\mathrm{Co}$ municación y Género. Facultad de Periodismo y Comunicación Social. Universidad Nacional de La Plata. E-mail: cremona23@yahoo.com
}

"A mí me pega por el lado de la calentura primero. Me enamoro de diversas personas todo el tiempo, que no quiere decir que pasen cosas o que yo actúe en función de eso. Por ahí me dura una semana y después se me va. Cosas que tienen que ver con una energía de la propia vida o del deseo, o no sé. Con algo que te gusta, y puede ser cómo te hablaron". (L., 34 años)

"Creo que el amor de enamoramiento es cuando una es feliz plenamente. Me pasa que todavía pienso en él y me saca sonrisas o me encuentro pensando en él. Y el embarazo me hizo sentir aún más enamorada, como que me sigue pareciendo increible tener un hijo que es fruto del amor con el chico que me gusta y el hombre que amo, me siento Cris Morena hablando así. Perdón”. (F., 32 años)

"Bueno, no sé si estoy enamorada la verdad, me mataron con la pregunta, pero sí sé que no es una constante nunca. Coincido con que son momentos. No sé, ayer estaba todo en equilibrio y era feliz, y hoy por una cosita, ya no. Y en ese sentido creo que estuve mil veces enamorada". (V., 30 años)

"A mí me pasa eso también. Creo que estuve enamorada muchas veces, pero también creo que el enamoramiento es más irracional, tonto, no real sobre la persona, es un momento muy recortado en el tiempo y en el espacio". (A., 30 años)

"No deja de ser un estado propio por más que se proyecte en alguien". (M., 30 años)

"Si bien cuando me peleé con alguna de esas personas, sufrí más, con otros menos, entonces ahí me preguntaba si medir el sufrimiento equivale al amor que sentía. Si sufro más es porque realmente estaba enamorada o me interesaba más". (S., 38 años)

"Para mí, estar enamorada es querer estar todo el tiempo con el otro, querer tocarlo, querer besarlo, querer estar cerca de su piel, y ahí es como me doy cuenta que estoy enamorada. Si no, no estoy enamorada. Y eso puede darse o con una pareja estable, o con una pareja inestable, que una siempre va a querer que pase a ser estable si siente esa sensación. Ese idilio. Yo me casé muy enamorada, o al menos eso creía. Porque después haciendo terapia una se da cuenta que confunde el amor con la seguridad, con la compañía”. (E., 49 años) 
"Enamorarme tiene que ver con fidelidad, incluso. Estoy como en un embole con el otro. Un ida y vuelta". (R., 46 años)

"A mí me ha pasado que me mueve el piso los primeros dos meses y después ya no. Entonces el enamoramiento es una etapa. Yo no puedo creer que eso haya sido amor porque, ¿por qué no continuó?”. (S., 38 años)

"Empecé a estar con él y tenía esa contradicción. Por un lado, me re gustaba, y por el otro, me quería matar. Porque el amor es hermoso, pero implica una dependencia". (U., 40 años)

El enamoramiento aparece como una potencia que se despliega por un período más o menos reducido en el tiempo -"una etapa", "son momentos"-, una activación del "yo" a través de su erotización, un movimiento transformador y revelador en el orden de la (auto) percepción; no como factor de sujeción, inseguridad y ansiedad de las mujeres. "Bajo la máxima de que el amor todo lo puede somos capaces de realizar grandes gestas, e incluso enfrentarnos a nosotros mismos, a nuestros miedos, defectos, debilidades (...) Es una forma de trascendencia espiritual" (Herrera Gómez, 2007: 8). Sin embargo, de acuerdo a los testimonios, "ese idilio", esa sensación de trascendencia rápidamente puede decantar en dependencia, apego al otro/a, riesgo de sufrimientos, y/o el vínculo adoptar la forma de un "amor-refugio" (Lancelin y Lemonnier, 2013: 231).

Si bien la informante E. asocia el amor con la seguridad, y el enamoramiento con la condición previa a esa situación de estabilidad emocional y vincular, la descripción de la sensación de enamoramiento alude a un estado de (re)afirmación subjetiva a través del deseo, incomparable a cualquier otro. También en líneas generales podemos distinguir una percepción diferencial de acuerdo a la edad: quienes rondan los 30 años lo vinculan a un estado efimero que no necesariamente se circunscribe o es condición previa a una relación formal y sostenida en el tiempo. Para las mujeres de mayor edad, 45-50 años, sí está vinculado al menos con la ilusión de construir algún tipo de lazo sexual y amoroso con esa persona, y que no sea una experiencia aislada. Incluso se anuda enamoramiento a una fidelidad entre amantes, "un ida y vuelta" que discurre, donde no hay espacio para terceros/as.

En el marco de la misma pregunta sobre el enamoramiento, una informante respondió: 
De Prácticas y discursos

Universidad Nacional del Nordeste

Centro de Estudios Sociales

Año 7, Número 10, 2018, Octubre

ISSN 2250-6942

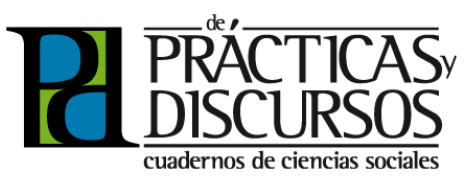

"Yo estoy en pareja hace casi 10 años, y lo pienso un montón. Nunca tuve muchas parejas, $y$ de pronto me puse en pareja, mucho después que amigas, compañeras. Me parecía que ya me quedaba sola porque si hasta los 25 o 30 no conseguiste, ¿viste cómo es todo eso? (...) Y la relación ahí quedó, en el mismo letargo. (...) Con mi pareja me pasó, cuando estábamos arrancando, de sentir esa angustia de no saber lo que va a pasar, si va a seguir o no, si va a tener una estabilidad o no. Y después cuando ya estaba todo más consolidado esa cosa de añorar. Creo que estamos atravesados por esto de que el amor tiene que ser como una efusión de placer. Entonces el saber la previsión de todo, era como: ¿'será que tengo que cambiar de pareja?', como para volver a sentir las cosas que otras parejas sienten". (A.L., 35 años)

Illouz explica esta suerte de malestar, insatisfacción, ansiedad y conflictividad insistente que se tiende a experimentar en relación con el amor, porque ha sido históricamente a través del "amor" que se produjo la sujeción y fijación del "yo" en las instituciones modernas, indudablemente configuradas por relaciones económicas y de género (IIlouz, 2012: 15). Sin embargo, ese estado anhelado de máxima estabilidad, una vez "alcanzado", deviene en una suerte de entumecimiento existencial o "letargo", que nada tiene que ver con la tranquilidad, la autorealización y la plenitud proyectada. Además, el testimonio da cuenta de la presión social, en este caso en el seno de su grupo de pares, que sobrellevan las mujeres por "conseguir una pareja estable". Un malestar que una vez en pareja deviene en "sentir lo que otras parejas sienten".

"También pasa que a medida que crecés, y seguís soltera, la presión social es más fuerte. Con el estar en pareja, tener novio, tener hijos, estar casado. Por parte de gente de mi edad, gente más grande, y gente más joven que no lo puedo creer. (...) Me afecta. No me genera un deseo. Por ahí lo que me genera es tratar de minimizar, o de enojada decir 'inah, el amor no existe!'. Retobarme ante eso. Generalmente la gente que opina no es la de mayor confianza. Y también está bueno ver cómo te afecta eso y porqué. Porqué te afecta lo que dice alguien que ni conocés". (S., 38 años)

El amor romántico como constructo cultural aparece en el siglo XII a través de la lírica y los trovadores. A través de la cultura oral la tematización describe un vínculo que es carnal, pasional, exclusivo y que aparece como irrenunciable. Anteriormente, los relatos pro- 
pios de la cultura popular centraban su atención en el amor cortés, que describe el vínculo fraternal entre caballeros que se honran con lealtad. Este proceso acompaña la transformación social a través de la cual se diluyen los lazos comunitarios y la familia se constituye como institución primaria. "La familia se convierte en un espacio cargado de sentimientos, para lo que se da también una cierta domesticación de la sexualidad" (Esteban y Távora, 2008: 60). Desde entonces, el amor romántico ha sido objeto temático de relatos populares diversos. Las novelas por entregas, los folletines y las telenovelas se ocupan de relatar historias de amor romántico atravesadas por el drama. Desde Romeo y Julieta hasta la película ganadora del premio Oscar en 2018, el amor aparece como un evento conflictivo que transforma la vida, a través del cual se alcanzará la felicidad, pero a cambio exige atravesar pruebas. Nuestras experiencias están condicionadas por los relatos mediáticos que consumimos a diario y que relatan el amor desde el drama. La informante A.L. se pregunta incluso si la ausencia de conflicto en la relación es sinónimo de la ausencia de amor.

En las reflexiones de U. y de A. también aparece esta noción del enamoramiento como un sentimiento natural, que genera una transformación en la vida cotidiana y puede hacernos más "tontos" o "dependientes".

\section{EL SACRIFICIO Y LOS TRABAJOS DOMÉSTICOS NO REMUNERADOS}

Frente a la segunda pregunta, relacionada con las acciones realizadas "por amor", las respuestas demoraron en aparecer. La pregunta parecía asociar amor a sacrificio y ninguna participante queria asumirse en esa posición. En la enunciación quedaba explicitada la cuestión de que la relación conyugal es asimétrica, o que en esos ejemplos puede haber una dimensión de violencia simbólica. Sin embargo, a medida que fueron participando y sintiéndose interpeladas entre ellas, la reflexividad sobre el hacer por amor, "hacer por el otro/a" Ilevó a una respuesta profunda sobre sus prácticas y modos de construir la pareja. En ese intercambio surgieron las siguientes ideas, confidencias, anécdotas:

“A mí me surge, en qué cosas no pude decir 'no". (M., 27 años)

"Yo crié dos hijas hermosas, por amor. Esperaba a mi marido sin ganas de cocinar, pero cocinaba igual, por amor, 
porque después lo veía y comía rico. Y me bancaba reuniones familiares espantosas, por amor. Espantosas porque no me bancaba la familia fundamentalmente. Conversaciones largas, tediosas, por amor. Muchas cosas. Hasta que un día dije, 'voy a pensar un poco en mí’.' (E., 49 años)

"Bueno, por ejemplo, a mí me molesta juntar su mugre, sus zapatillas y ahí sí discutimos, me re caliento. Eso sí. Pero lavarle la ropa, y que tenga la ropa limpia para ir a trabajar, yo me siento feliz con eso. De que él se despreocupe de esa parte. Como que él a mí me espere con el almuerzo". (T., 34 años)

"Una vez le organicé un cumpleaños cuando recién nos mudamos juntos, un cumpleaños donde cociné doce pizzas y una torta, y después él nunca me organizó, entonces se lo reclamo todo el tiempo". (A.L., 35 años)

"Eso en mi pareja se llama 'los domingos'. Yo prefiero estar afuera y ella quedarse adentro, y bueno, sale conmigo a hacer algo afuera. Para ella, lo mejor del domingo era quedarse todo el día en pijamas y mirar Los Simpsons. De hecho, ya se acostumbró, y es ella la que sola sale del modo pijama y pregunta: ‘a dónde querés que vayamos?'. Yo eso lo reconozco. Es una negociación". (A., 30 años)

“Ay, esa pregunta! (risas). No lo visualizo tan bien como lo que yo hice. Y 'FR' (nombra a su pareja) veo que hace boludeces, por ejemplo, ir a comer un domingo a la casa de mi papá. Para él es un bajón. Ahora ya está mucho más naturalizado, pero al principio que venga mi hermano a mi casa a tomar mate, también fue un bajón. Porque hace seis años que vive solo, le costó asumir que estaba en pareja con alguien". (F., 32 años)

"No sé, ir al cumple de tíos, abuelos, sin tener ganas". (V., 30 años)

"Estaba recordando, yo tenía una pareja a la que le gustaba mucho el fútbol y todos los domingos a la noche en esa época, en los 90, se miraba un programa de fútbol muy conocido, $y$ yo disfrutaba junto con él, en la cama, después del domingo... como que esperaba eso. Y hoy lo odio. ¡Fútbol de primera! (...) Bueno, pero cuando me separé me vi extrañando esa posibilidad de ver juntos Fútbol de primera”. (L., 49 años) 
Al indagar en torno a los actos y gestos "por amor", se describen fundamentalmente negociaciones que implican abnegaciones, resignaciones y concesiones múltiples. Hay un reconocimiento inmediato de la dimensión sacrificial del amor, que pareciera recaer con más peso en las mujeres. Ellos "hacen boludeces": la informante F. identifica como un gesto de amor por parte de su novio el hecho de recibir en su casa y compartir mates con su cuñado. Muchas directamente manifestaron la dificultad de encontrar los mismos actos o gestos, sutiles o no, por parte de sus compañeros varones hacia ellas, vislumbrando un grado de implicación diferencial en "el proyecto en común". Si bien no expresan que el amor implica sacrificios, durante la enunciación misma se revela que han realizado -o dejado de realizar- tareas por la única razón de hacer feliz al otro. Participar de reuniones familiares "tediosas", organizar cumpleaños, ocuparse del cuidado del otro(s), ver partidos de fútbol.

La respuesta de $\mathrm{S}$. realiza una vinculación directa con la cultura mediática de la infancia, en la que aparecen representadas las formas relacionales románticas:

"Sí, y yo creo que si estás enamorado de alguien por amor hacés todo. No hay algo concreto que hagas por amor. (...) Es muy de Disney eso del 'por amor"'. (S., 38 años)

Nuevamente lo mediático aparece como un modelo formativo que interpela para identificarse, o para rechazar la propuesta. La pareja se enuncia como un vínculo en el que las relaciones de poder quedan difusas, maquilladas bajo el velo de lo emocional. Es ilustrativo el testimonio de E., divorciada después de 18 años de casada:

"A mí un día ¿sabés lo que me pasó? Me di cuenta que, por mí, por amor, no se hacía nada. Y ahí es cuando dejé de hacer cosas por amor, cuando empezás a poner en la balanza. Pasan unos años y empezás a analizar de manera más fría qué hizo el otro por vos, por amor. Y caés en la cuenta, yo caí, no quiero generalizar, que yo muchas veces pedía compañía y el otro se iba a jugar al fútbol, al rugby, al minipool, a lo que sea, y no se quedaba conmigo. Cuando había dos gustos, por ejemplo, a mí me gustaba ir a la playa, y a él hacer asados los domingos. Y toda mi vida comí asados, y nunca fuimos a la playa. Cuando me di cuenta de eso, dije: 
De Prácticas y discursos

Universidad Nacional del Nordeste

Centro de Estudios Sociales

Año 7, Número 10, 2018, Octubre

ISSN 2250-6942

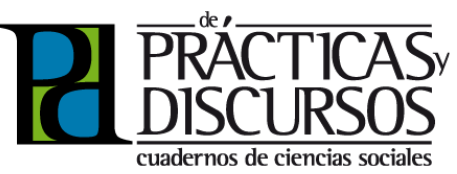

'Bueno, ya está. Empezó un proceso largo. Empecé a ir a la playa los domingos, dejando mi familia, con el gran asado, $y$ me iba a la playa con una manzana". (E., 49 años)

El problema no reside entonces solo en los sacrificios que parecen constitutivos del amor romántico, sino en que tales sacrificios afectan, comprometen desigualmente a unas y otros, al punto de trazar notables asimetrias de poder, que pueden percibirse irreversibles. No hay que olvidar que ese lugar de subalternidad femenina se sostiene durante años a costa de recompensas, condecoraciones y reconocimientos sociales.

Que el amor resulte tan atrayente para las mujeres es porque implica la promesa de recibir un estatus moral y una dignidad que les es negada en otros ámbitos sociales, además de enaltecer su destino social de cuidar y amar a los otros/as como madres, esposas y amantes. La categoría de "madresposas" propuesta por Marcela Lagarde condensa en buena parte las cualidades (y funciones) múltiples del sujeto femenino, producto del amor burgués. Refiere a las mujeres especializadas en ser madres y ser esposas, cuyo objetivo vital se desdobla en tres (mandatos): ligarse sexo-afectivamente con un hombre, tener hijos/as y constituir una familia. "En la modernidad las madresposas ya hacen también otras cosas, (...) pero lo vital para su identidad femenina son estos tres mandatos (2005: 401-402).

Sin embargo, el concepto -y la experiencia- de la "madresposa" puede encerrar malestares que logren resquebrajar el vínculo de pareja. Los motivos desencadenantes son diversos y se fusionan con aspectos singulares de cada vínculo y cada mujer. En el caso de E., los malestares y la ficción de "la paridad" se evidenciaron primeramente a partir de la desigualdad de poder en la toma de decisiones, la no contención de sus intereses y preferencias, la no canalización de sus propuestas y la desvalorización de su palabra. Se deshace la estabilidad e incluso la sensación de "completud", social, psíquica y emocional, que parecía garantizar el lugar de "madresposa", y toma lugar la angustia al saberse solas y desconsideradas en sus ideas y que-haceres.

Por momentos toma lugar la idea de amor asociada al concepto de trabajo ("el trabajo de aguantar al otro"). Incluso, en algunas historias, como la de E., que ha sido esposa y ama de casa durante casi dos décadas, pero también la de $F$., quien convive con su novio desde hace alrededor de un año, aquello que denomi- 
namos sacrificio por amor, bien podría definirse como trabajo reproductivo no asalariado. Sus tareas y acciones han movilizado y movilizan una gran cantidad de trabajo que no fue ni rentado, ni reconocido, pero sí funcional al sostenimiento económico de sus hogares. Se habla de una "feminización del trabajo doméstico, no solo por motivos cuantitativos (lo efectúan en su mayoria mujeres), sino cualitativos, en tanto lo que hacen las mujeres, y su cadena de significantes atribuidas a lo femenino, 'vale menos'"' (Lerussi, 2016: 149).

Una re-lectura feminista del capitalismo no solo es interesante para pensar el rol crucial de las mujeres en la reproducción del capital, sino también para visualizar cómo su afincamiento en "lo doméstico" ha significado un modo de disciplinamiento sexual. "El trabajo doméstico no sólo se le ha impuesto a las mujeres, sino que ha sido transformado en un atributo natural de nuestra psique y personalidad, una necesidad interna, una aspiración proveniente de las profundidades de nuestro carácter de mujeres" (Federici, 2013: 37). Los atributos de la feminidad se traducen en funciones laborales en sentido estricto. Habitar la condición de "mujeres", socialmente aceptables, supone el desarrollo diario de un tipo de trabajo, creado y aprovechado por el capital para la reproducción de su fuerza de trabajo.

Esteban y Távora retoman los aportes de Levinton para señalar que son los mismos rasgos culturales de lo femenino que configuran nuestra subjetividad "los que remiten a la abnegación, a ponerse al servicio de los otros, a la postergación y renuncia de los deseos y proyectos personales, a la sobrevaloración de la pareja y la familia" (2008: 65).

\section{(Diálogo)}

"Igual, para mí, el amor también es un trabajo. Implica un esfuerzo que uno le pone, con toda la alegría del mundo, pero para que una relación de pareja se mantenga". (F., 32 años)

“Claro, por eso yo no tengo más ganas de trabajar". (E., 49 años)

Aparece naturalizado el hecho de que estar en pareja implica esforzarse por hacer feliz a otro/a, incluso en detrimento de los propios intereses. De este modo, el tiempo libre se enuncia como un capital posible de ofrendar hacia la pareja para compartir del 
De Prácticas y discursos

Universidad Nacional del Nordeste

Centro de Estudios Sociales

Año 7, Número 10, 2018, Octubre

ISSN 2250-6942

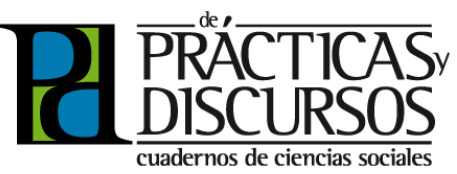

modo que ese/a otro/a desee o para realizar tareas domésticas que generen un bienestar en el/la otro/a. "Acciones por amor", en las que muchas se han sentido identificadas -ver un partido de fútbol, cocinar para su familia, etc.-, no eran disfrutadas por ellas, pero aparecian como parte necesaria de estar en pareja y como modo de demostrar/hacer tangible ese amor. "Esta peculiar combinación de servicios físicos, emocionales y sexuales que conforman el rol de las amas de casa es lo que hace su trabajo tan pesado y al mismo tiempo tan invisible" (Federici, 2013: 38). Cuando prevalece esta percepción "necesaria" y "natural" sobre su propio trabajo en la casa, es justamente cuando se le expropia su componente político, su valor social y económico.

\section{PROYECTOS DE VIDA}

Frente a la última pregunta acerca de sus proyectos de vida, en los testimonios de las mujeres que transitan los 30 y ya están en pareja, el matrimonio no fue nombrado como un hecho obligatorio, ni deseado. De hecho, muchas de ellas ni siquiera lo mencionaron como posibilidad. Sin embargo, todas hicieron explícito que se imaginaban en pareja al proyectar un futuro cercano. El horizonte de realización con respecto a las generaciones más grandes se diferencia en la idea de durabilidad del amor y de la importancia de su institucionalización: las mujeres más jóvenes no buscan un amor para toda la vida, ni expresan intensiones de contraer matrimonio. Sin embargo, continúa apareciendo el anhelo de compartir la vida con una pareja.

El sistema capitalista enseña a vivir de a dos. La industria cultural y la estructura económica alientan la organización de los proyectos a futuro en parejas. Si bien el matrimonio igualitario y las familias monoparentales parecen poner en jaque el imaginario tradicional de familia, es esta institución moderna la que moldea los proyectos a largo plazo.

"Espero verme como más segura, más plantada. ¿Dónde?, calculo que en Mar del Plata o en algún lugar que me haga feliz.

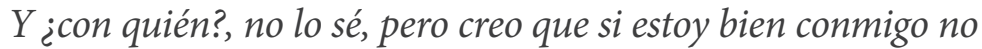
me tendría que interesar tanto"'. (S., 38 años)

Mirá, me puedo llegar a ver con un hombre, pero sigo insistiendo que tiene que ser un hombre que me mueva el piso. 
Yo por estar acompañada no voy a estar con ningún hombre. Tengo pretendientes y soy la mayor, pero no me caben (risas). Me veo muy feliz con alguien que me haya movido el piso y tenga la capacidad de aceptar mi vida, con mi familia, mis hijos, mis nietos, y si no es así querida, estaré sola”. (E., 49 años)

"No me imagino separada. Me veo en construcción con esa otra persona que le salgan canas, como a mí”. (J., 35 años)

"Me gustaría algo similar a ahora, en pareja, con la actual u otra”. (V., 30 años)

"En este momento me puedo imaginar con mi pareja actual, pero... sí, creo que me veo en pareja (...) ¿Puedo ser más superficial? Quisiera tener más estabilidad laboral para poder proyectar cosas más concretas. Viajar, por ejemplo, iy me encantaría que mis amigas se dejen de reproducir y podamos viajar juntas! ( $A$., 30 años)

En estas mujeres, el matrimonio ya no aparece como institución necesaria para la supervivencia económica, ni para acceder a la vida pública y sostener un capital social. Sin embargo, siguen vigentes y en reactualización esas interpelaciones (identificaciones, rechazos) frente al matrimonio o al "proyecto de vida con un compañero/a, pareja". Las entrevistadas que no estaban en pareja expresaron cierta ansiedad por la conyugalidad, el formar pareja, construir un proyecto de vida a través de ese vínculo. Incluso, cuando A. pregunta si puede "ser más superficial" para responder y plantea su deseo de viajar y tener estabilidad laboral, está reafirmando que los proyectos mencionados por las otras participantes son más profundos. Como si fuera una estrategia discursiva para no responder acerca de cuál es su deseo más profundo, y por ello menciona otros "más superficiales".

Todas manifestaron sentirse afectadas directa o indirectamente por la demanda social: "¿para cuándo un novio?", "¿para cuándo el bebé?". La falta de pareja aparece en los imaginarios como un estado transitorio y no como un horizonte de deseo.

"Me gustaría recuperar mi autonomía e irme de viaje con una amiga, o unas. Me parece súper importante mantener mi identidad. O sea, estoy entregada a ser mami ahora, compañera, buenísimo. Pero nunca perder eso de meta. De poder 
De Prácticas y discursos

Universidad Nacional del Nordeste

Centro de Estudios Sociales

Año 7, Número 10, 2018, Octubre

ISSN 2250-6942

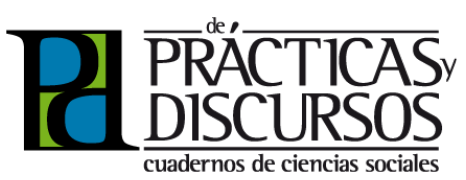

volver a ser quien fui en un principio. $Y$ lo hablo con mis amigas y a todas nos pasa lo mismo. Esto (ser madres y vivir con la pareja) nos encanta y nos hace re felices, pero poder volver a ser quien soy. Nunca estuve tan enamorada y feliz, tan conectada conmigo y con el otro, pero creo que, si yo soy feliz, hago feliz al que tengo al lado, y a mis hijos. Estoy hablando de acá a un tiempo, ya cuando mi hijo vaya a la Facultad y se haga la comida solo. Y se quede con sus hermanos o su padre. Pero me parece que la construcción del amor te tiene que poder llevar a ese lugar". (F., 32 años).

Por último, destacamos en el testimonio de F., donde se enuncia en términos explícitos una postergación del "yo", de los proyectos identificados como autónomos, en beneficio de la consolidación del lugar social de la madre y esposa, nuevamente aparece la familia como la prioridad para la realización individual. Es interesante que al plantear este deseo F. no habla por sí sola, sino que se ubica dentro de una grupalidad: "Hablo con mis amigas y a todas nos pasa lo mismo". En esta idea hay una arraigada naturalización de que las mujeres que maternan dejan de ser para ellas y durante un período de su biografía son para otros/as. La maternidad y crianza de hijos/as fue un tópico satélite en ambos grupos focales. Si bien la investigación no se propuso indagar en la temática, en las conversaciones se mencionó más de una vez como un aspecto central de la biografía de las participantes, tanto de quienes eran madres, como de quienes estaban reflexionando si querían serlo.

\section{CONCLUSIONES}

El amor romántico como producto cultural e histórico es formativo de la subjetividad de las mujeres. Los relatos recogidos ilustran cómo continúa enunciándose como una experiencia deseable y ordenadora de la biografía de las mujeres. El amor de pareja aparece en las imágenes de futuro como un anhelo que simboliza la felicidad. Para las entrevistadas, la dimensión de compartir y ser con otros en forma relacional es una prioridad. En la mayoría de los casos analizados, la pareja o la familia.

Estar en pareja es sinónimo de poseer un bien simbólico y material que demanda a cambio trabajo, abnegación y sacrificio. El imaginario de la mujer recluida en el ámbito privado y sin posibi- 
lidad de decisión ya no está vigente en buena parte de las mujeres de clase media, urbana y universitaria; sin embargo, la pareja continúa siendo un horizonte de expectativas y realización. En los discursos, ese otro/a no aparece como alguien que viene a completarnos, pero sí como un anhelo, un deseo profundo, o incluso una estabilidad emocional.

Estar sin pareja se enuncia, en cambio, como un estadio transitorio hasta encontrar a una persona que cumpla con los requisitos necesarios. Varias informantes señalaron que a medida que pasan los años sienten que hay una expectativa social sobre ellas para que encuentren una pareja con quien vivir y tener hijos/as. Si bien no expresaron que esta situación modifique sus prácticas o su felicidad, sí les produce agobio el señalamiento por parte de los demás acerca de estar fuera del rol que se les asigna. S. manifestó: "con los años, la presión social crece". La edad aparece como un condicionante, a medida que cumplen años se sienten menos elegibles: A.L. expresó: "ya pensaba que me quedaba sola", E. comentó que luego de su separación pensó: "bueno, me voy a quedar sola, tengo que tener una pareja". El éxito o fracaso de la mujer -en particular- sigue asociado al formar una pareja y una familia, pese a las modificaciones respecto del significante tradicional de amor romántico.

Bajo la noción de amor se ocultan relaciones de poder asimétricas que se traducen, por ejemplo, en la desigualdad que implica el trabajo doméstico y el acompañamiento emocional. Ser madresposa implica realizar tareas que son naturalizadas e invisibilizadas porque se entienden como propias de estar en pareja: organizar un cumpleaños, cocinar para el otro, ver los programas de tele que el otro elige.

En las respuestas apareció cierta resistencia a pensar el amor como una relación que exige sacrificios; sin embargo, se enunció en más de una oportunidad como un trabajo. Estas tareas que se leen como parte de estar en pareja, como negociaciones propias de toda relación humana, son elegidas y quizás respondan a que las mujeres son educadas socialmente para consentir a otro. Cuando la informante E. revisó críticamente su experiencia, enunció esas instancias como la anulación de su subjetividad. Lo que determinó su separación fue encontrar que ese trabajo que realizaba a diario constituía una violencia simbólica y no le generaba más felicidad.

Los consumos mediáticos no fueron un eje de análisis de los gru- 
pos focales; sin embargo, aparecieron referencias a Cris Morena o a Disney como formadoras de los imaginarios sobre el amor. Analizar las experiencias de sus relaciones en articulación con la producción y el consumo de bienes culturales y mediáticos de la actualidad permitirá comprender los relatos de experiencia con otro espesor; elucidando cómo el "amor romántico" se transforma y al mismo tiempo permanece como horizonte de deseo.

\section{BIBLIOGRAFÍA}

ADAMOVSKY, E. (2009). Historia de la clase media argentina. Apogeo y decadencia de una ilusión, 1919-2003. Buenos Aires: Planeta.

AMIGOT LEACHE, P. Y PUJAL I LLOMBART, M. (2009). Una lectura del género como dispositivo de poder. Sociológica, (24)70, mayo-agosto, 115-151. México: Universidad Autónoma Metropolitana Distrito Federal. Disponible en http://www.redalyc.org/pdf/3050/305024677005.pdf

CHANTEFOR, P. (2017). Reseña: La mujer de la ilusión. Pactos y contratos entre hombres y mujeres. EIKASIA, 75, 379-384.

CHAVES, M. (2005). Juventud negada y negativizada: Representaciones y formaciones discursivas vigentes en la Argentina contemporánea. Última década, 23. Disponible en linea: https://scielo.conicyt.cl/scielo.php?pid=s071822362005000200002\&tscript=sci_arttext

CREMONA, M.F. (2016). La articulación educación, comunicación y género. Documento de Cátedra. Comunicación y Educación Cátedra II. La Plata: Editorial Facultad de Periodismo y Comunicación Social.

FERNÁNDEZ, A.M. (1993). La mujer de la ilusión. Barcelona: Paidós.

FEMENÍAS, M.L. (2009). Consolidar la mirada con perspectiva de género. Necesidad de un punto de vista generizado. Revista Tram(p)as de la comunicación y la cultura, 20-24. Buenos Aires: FPyCS-UNLP. 
FICOSECO, V.S. (2014). Experiencias de mujeres, virtualidad y género. Usuarias del entorno virtual de aprendizaje de la Universidad Nacional de la Patagonia Austral, Unidad Académica San Julián. Tesis doctoral, FPyCS, UNLP.

ESTEBAN, M.L. Y TÁVORA, A. (2008). El amor romántico y la subordinación social de las mujeres: revisiones y propuestas. Anuario de Psicología, 39, 1, 59-73. Barcelona.

FIGARI, C. (2009). Eróticas de la disidencia en América Latina. Argentina: Ciccus.

GÓMEZ-ESCALONILLA, G.; HUERTAS BAILÉN, A. Y MARTÍNEZ SUÁREZ, Y. (2012). Reflexiones sobre la aplicación de la técnica del Focus Group en el estudio de los procesos de sociabilidad juveniles en contextos multiculturales. Actas del $2^{\circ}$ Congreso Nacional sobre Metodología de la Investigación en Comunicación, Simposio Internacional sobre Política Científica en Comunicación, Segovia, 2-3 mayo.

HERRERA GÓMEZ, C. (2007). Los mitos del Amor romántico en la cultura occidental. Madrid: El Rincón de Haika.

Illouz, E. (2012). Por qué duele el amor. Una explicación sociológica. Madrid: Katz Editores.

LANCELIN, A. Y LEMONNIER, M. (2013). Los Filósofos y el amor: de Sócrates a Simone de Beauvoir. Buenos Aires: El Ateneo.

LAGARDE DE LOS RÍOS, M. (2005). Claves feministas para mis socias de la vida. Madrid: Horas y horas.

MORIN, E. (1998). Complejo de amor. Gazeta de Antropología, 14.

PALUMBO, M. (2015). Las dinámicas de la violencia contra las mujeres y el amor en los primeros noviazgos juveniles en el Área Metropolitana de Buenos Aires. Tesis de Maestría en Investigación en Ciencias Sociales, Facultad de Ciencias Sociales de la Universidad de Buenos Aires.

(2017). Experiencias de amor y violencia en los primeros noviazgos juveniles. Estudios Feministas, 25, 1329-1346. 
PATEMAN, C. (1988). El contrato sexual. Barcelona: Antrophos.

PRECIADO, P. (2009). Terror anal. Apuntes sobre los primeros días de la revolución sexual. Epílogo a la versión castellana del texto de Hocquenghem, G. (2000). El deseo homosexual (pp. 136-174). Barcelona: Melusina.

RODRÍGUEZ MAGDA, R.M. (1999). Foucault y la genealogía de los sexos. Barcelona: Anthropos.

RODRÍGUEZ SALAZAR, T. (2012). El amor en las ciencias sociales: cuatro visiones teóricas. Culturales, 8, 15, 155-180.

SUNIGA, N. Y TONKONOFF, S. (2012). Lenguaje, deseo y sociedad: Ios aportes de Julia Kristeva. Jornadas de Sociología de la UNLP, La Plata, 5-7 diciembre.

SCOT, J. (1996). El género: una categoría útil para el análisis histórico. En Lamas, M. (comp.) El género: la construcción cultural de la diferencia sexual. México: PUEG-UNAN Ángel Porrúa.

(2008). Gender: a Useful Category of Historical Analisys. American Historic Review, Vol 113, 5 de noviembre. Disponible en http://www.debatefeminista.cieg.unam.mx/wpcontent/uploads/2016/03/articulos/040_08.pdf 